\title{
Mental Health Act Code of Practice
}

\section{Consent of 16- and 17-year-olds to admission and treatment}

\author{
Andrew Parkin
}

The revised Code of Practice to the Mental Health Act 1983 (England and Wales) was published on 1 March 1999 (Department of Health \& Welsh Office, 1999), and came into force on 1 April 1999. This code of practice replaces the previous one (Department of Health \& Welsh Office, 1993) in providing guidance to professionals undertaking duties under the Mental Health Act 1983. The Mental Health Act uses the term 'patient' irrespective of age. However, Section 10 (2) of the Act sets out the right of 16- and 17-year-old people to determine their own admission. Section 10 states:

"1. Nothing in this Act should be construed as preventing a patient who requires treatment for a mental disorder from being admitted to any hospital or mental nursing home in pursuance of arrangements made in that behalf and without any application, order or direction, rendering them liable to be detained under this Act or from remaining in any hospital or mental nursing home in pursuance of such arrangements after he has ceased to be liable to be so detained. 2. In the case of a minor who has attained the age of 16 years and is capable of expressing his own wishes. any such arrangements as are made in Sub-Section 1 (above) will be made, carried out and determined notwithstanding any right of custody or control vested in law by his parent or guardian."

Black et al (1991) observed that this is congruent with the Family Reform Act (England and Wales) 1969. Section 8 of the Family Reform Act also states that consent of 16- and 17-yearold people to their own medical or dental treatment is effective.

Chapter 31 of the 1999 Code of Practice addresses special issues relating to children and young people under the age of 18 (this corresponds to Chapter 30 of the 1993 Code of Practice). Both Codes of Practice define children as those under the age of 18 years.

\section{The 1993 Code of Practice}

The right of a minor who had attained the age of 16 to refuse medical treatment when consent has been given by a person or body holding parental responsibility is not addressed directly by either the Mental Health Act 1983 or the Family Law Reform Act 1969. Guidance was provided on this in the previous 1993 Code of Practice, but this was neither internally consistent, nor in line with good practice. There was an inconsistency with regard to consent by 16-17-year-old people in that they were able to admit or discharge themselves, but were unable to refuse consent to treatment when consent had been given by the person or body with parental responsibility.

Paragraph 30.6 of the 1993 Code of Practice, with regard to young people aged 16-17, states that:

\begin{abstract}
"Anyone in this age group who is "capable of expressing his own wishes' can admit or discharge himself as an informal patient to or from hospital, irrespective of the wishes of his parents or guardian."
\end{abstract}

However, paragraph 30.7(d), "refusal of a minor to consent to treatment", states:

"No child of whatever age has authority by refusing consent to treatment to override a consent to treatment by anyone who has parental responsibility (which includes a Local Authority under a Care Order) or a consent by the court."

Thus, the 1993 Code of Practice suggested that children as old as 17 could be treated without their consent, providing that a body or person with parental responsibility has given consent to that treatment, without invoking the Mental Health Act. However, this did not sit comfortably aside Paragraph 30.6 as quoted above, nor did it reflect good practice.

This was also at variance with Paragraph 30.2

(b) of the 1993 Code of Practice which stated:

"Unless statute specifically overrides, young people should genuinely be regarded as having the right to make their own decisions (and in particular treatment decisions) when they have sufficient understanding and intelligence." 


\section{The 1999 Code of Practice}

The current 1999 Code of Practice does not include the statement contained in paragraph 30.2(b) of the 1993 Code of Practice. This improves the internal consistency of the Code of Practice, but in the direction of reducing the authority of 16- and 17-year-old people to determine their treatment in cases where the Mental Health Act would not be invoked.

The discrepancy whereby a 16- or 17-year-old may refuse admission, but not treatment remains. Such a young person's refusal to admission is addressed in one sentence which appears in Section 31.8 of the current 1999 Code of Practice:

"Where a 16- or 17-year-old is unwilling to remain in hospital as an informal patient. consideration may need to be given to whether he or she should be detained under the Act."

However, the refusal of a 16- or 17-year-old to be treated is addressed in paragraph 31.16 of the current 1999 Code of Practice:

"The refusal of a competent 16- or 17-year-old to be medically treated can be overridden by their parents or other person who has parental responsibility for that 16- or 17-year-old, or by the court. Consideration should be given to whether the use of Act, if applicable, would be appropriate."

The retention of the phrase "can be overridden by their parents or the person who has parental responsibility" creates the inconsistency between the young person's rights to determine treatment and to determine admission. It also creates an inconsistency between the guidance given and good clinical practice as discussed below.

\section{Discussion}

Hoggett (1984) noted that the Mental Health Act is rarely used in the admission or treatment of minors. Hoggett suggests that this reflects the supposition that parents have the right to admit a child to hospital. However, this supposition should be reviewed in the light of the empirical evidence on the perceived competence of children clinically and in law. Interestingly, this evidence relates to children below the age of 16 years. The competence of children to assess clinical issues relevant to them and their competence to give consent can be assessed by the clinician. An understanding of the nature of the disorder and the likely outcome with and without treatment are the crucial features. Indeed, this should be a feature of good clinical practice, irrespective of age. That children can do this is supported by research evidence: 14-year-olds show no discernible difference in their competence at assessing hypothetical treatment dilemmas compared with adults when rated using a structured interview, whereas nine-year-olds do (Weithorn \& Campbell, 1982). The competence of children as witnesses has also been demonstrated (Spencer \& Flin, 1990; Dent \& Flin, 1992).

In considering children's competence in law, there is evidence in both statute and case law to suggest that children are competent. A precedent is set in case law (Gillick $v$. West Norfolk and Wisbech Health Authority and the Department of Health, 1986) whereby the child's consent can override the parent's wishes. Although evidence was not specifically examined in this case to determine the right of the child to refuse treatment in law, Lord Scarman stated in his summing up on this case. "Parental rights wield to the child's right to make his own decisions when he reaches sufficient understanding and intelligence to be capable of making up his own mind on the matter requiring decision". The principles of this are enshrined in the Children Act 1989. However, the Children Act merely guides professionals to take the child's wishes into account.

These issues have to be further considered in the case of Re: W. (A minor) (Medical Treatment: Court's Jurisdiction) (1992). In this case a 16year-old girl diagnosed as having anorexia nervosa was transferred against her wishes under the High Court's jurisdiction to a specialist unit for treatment.

Accepted clinical practice and legal guidance should not be based upon the supposition that Hoggett observed, but rather supported by sound empirical evidence. This in turn should provide the basis to statute law and its guidance. However, the 1999 Code of Practice falls to reflect either source of evidence.

Current guidance on consent to treatment without recourse to the Mental Health Act as set out in the 1999 Code of Practice remains potentially confusing and is inconsistent with good practice. The Mental Health Act Commission is well placed to monitor current practice and to identify cases which demonstrate these inconsistencies. At present there is no specific mechanism for identifying children and young people under the age of 18 , though such a proposal could be within the remit of the Commission.

\section{References}

BLACK, D., WOLKIND, S. \& HENDRIKS, J. H. (eds) (1991) Child Psychiatry and the Law (2nd edn). London: Gaskell.

DENT. H. \& Fun, R. H. (1992) Children as Witnesses. Chichester: Wiley.

DEPARTMENT OF HEALTH \& Welsh OFFIC (1993) Code of Practice to the Mental Health Act 1983 (Pursuant to Section 118 of the Act). London: HMSO. 
- \& - (1999) Code of Practice to the Mental Health Act 1983 (Pursuant to Section 118 of the Act). London: The Stationery Office.

HoGGETT, B. (1984) Mental Health Law (Second Edition). London: Sweet \& Maxwell.

SPENCER, J. R. \& FUN, R. H. (1990) The Evidence of Children. London: Blackstone.

WETtHORN, L. A. \& CAMPBEL, S. B. (1982) The competency of children and adolescents to make informed treatment decisions. Child Development, 63, 1589-1598.
GILLCK v. West NoRfolk AND WisBech HeALTH AUthortT (1986) I AC 112, HL

Re: W. (A minor) (Medical Treatment: Court's Jurisdiction) (1992) WLR, 758.

Andrew Parkin, Senior Lecturer in Child Psychiatry, Greenwood Institute of Child Health. Westcotes House, Westcotes Drive, Leicester LE3 OQU

\section{Recent Topics from Advances in Psychiatric Treatment: Volume 2 Affective and Non-Psychotic Disorders} Edited by Alan Lee

This book discusses the evidence-based assessment of deliberate self-harm, and covers the special problems of general psychiatric practice when alcohol misuse and severe personality disorder complicate the picture. Chapters relating to

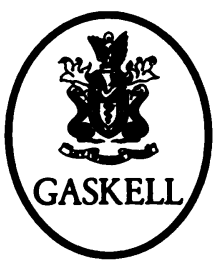
depressive disorders begin by focusing on opportunities for psycho-social intervention and liaison with primary care. There are comparisons of 'old' and 'new' antidepressants, and reviews of strategies for preventing relapse and recurrence, and managing resistant depression. The special problems of emergency treatment and depression in older patients are identified.

There are expert overviews of brief dynamic psychotherapy, cognitive approaches to treatment, lithium therapy and modern ECT practice. Many chapters emphasise the importance of the rational integration of biological and psychological treatments. There is helpful advice on the specific problems in managing obsessive-compulsive disorder and eating disorders, in dealing with somatisation, and in providing support and treatment for the victims of severe trauma.

\section{October 1999, £15.00, 160pp, Paperback, ISBN 190124217 X}

Royal College of Psychiatrists, Book Sales, 17 Belgrave Square, London, SW1X 8PG Tel: 01712352351 ext 146, Fax: 0171245 1231, 9.30am - 2.00pm. 